\title{
Configuration of the circle of Willis and its two parts among Egyptian: a magnetic resonance angiographic study
}

\author{
S.M. Zaki'1, 2, M.H. Shaaban², W.A. Abd Al Galeel1,2 , A.A.W. El Husseiny² \\ ${ }^{1}$ Fakeeh College for Medical Sciences, Jeddah, Saudi Arabia \\ 2Department of Anatomy and Embryology, Faculty of Medicine, Cairo University, Cairo, Egypt \\ [Received: 30 January 2019; Accepted: 6 February 2019]
}

Background: We hypothesized that the collateral circulation differs in different ethnic groups. So, the aim of our work was to study variations of the circle of Willis (COW) among Egyptian and to compare our findings with the findings of other nationalities.

Materials and methods: One hundred patients were studied using magnetic resonance angiography (3D-TOF-MRA). Frequency and morphologic variations in COW were studied. The diameters of the arteries of the anterior and posterior circle were verified. Finally, the differences among the mean diameters of these arteries regarding age and sex were also studied.

Results: Complete, partially complete and incomplete COW were encountered in $28 \%, 38 \%$ and $34 \%$ in the studied cases. The incomplete anterior circle was found in 34\% (10\% isolated incomplete anterior circle and $24 \%$ combined incomplete anterior and posterior circles) and the incomplete posterior circle came across in 62\% (38\% isolated incomplete posterior circle and 24\% combined incomplete anterior and posterior circles). Seven anterior circle variations were found. The commonest type was the classical type "a" with a prevalence of 56\%, being higher in male (57.1\%). The $2^{\text {nd }}$ common type was type " $g$ " (hypoplasia or aplasia of the anterior communicating artery) with a prevalence of $24 \%$, being higher in male (66.7\%). Six posterior circle variations were found. The commonest variation was the classic type "a" with a prevalence of $26 \%$, being higher in male (61.5\%). Posterior circles types " $d, e, h$ " (18\%, 24\%, 20\%) constituted $62 \%$ and were characterised by hypoplasia/absent of the posterior communicating arteries. Conclusions: The prevalence of complete COW (classic or textbook type) was encountered only $28 \%$ of the studied cases. Variations of COW were found to be more common in the posterior circulation (62\%). The incomplete anterior circle was found in 34\% and it is mostly caused by hypoplasia or aplasia of the anterior communicating artery which was found to be more common compared to the literature. (Folia Morphol 2019; 78, 4: 703-709)

Key words: circle of Willis, variations, Egyptian

\section{INTRODUCTION}

Circle of Willis (COW) is an anastomotic arterial ring that exists at the base of the brain. It compris- es the posterior cerebral arteries (PCAs), posterior communicating arteries (PcomAs), internal carotid arteries (ICAs), anterior cerebral arteries (ACAs) and

Address for correspondence: Dr. S.M. Zaki, Faculty of Medicine, University of Cairo, Cairo, Egypt, Current address: Fakeeh College for Medical Sciences, Jeddah, Saudi Arabia, e-mail: zakysherif1@gmail.com 
anterior communicating artery (AcomA) [5]. The ICAs and their branches that supply the anterior portion of the brain referred to as the anterior circulation. Whereas, the vertebrobasilar system that supplies the posterior portion of the brain referred to as the posterior circulation [18].

Many variations of $\mathrm{COW}$ were detected. Such variations reduce the collateral availability and increase the risk of transient ischaemic attacks and stroke in cases of severe stenotic ICA. Knowledge of the compensatory capacity of the COW is also important for neurosurgeons, vascular surgeons and interventional radiologists [10].

Formerly, the studies concerning COW were based on the autopsy findings. Many studies have established that three-dimensional time-of-flight (3D-TOF) magnetic resonance angiography (MRA) is a sensitive, noninvasive modality suitable for detecting the anatomy of COW [14]. Also, it provides an anatomical basis for future prognosis and treatment of cerebrovascular diseases [21].

We hypothesized that the collateral circulation differs in different ethnic groups. So, the aim of our work was to study the frequency and morphologic variations in COW among Egyptian using 3D-TOF-MRA and to compare our findings with the findings of other nationalities. The diameters of the arteries of the anterior and posterior circle were verified. Finally, the differences among the mean diameters of these arteries as regards to age and gender were also shown.

\section{MATERIALS AND METHODS}

One hundred patients of both sexes (64 males and 36 females) were included in the study. Patients diagnosed with cerebrovascular diseases, brain tumours or any significant pathological vascular brain abnormalities as well as trauma were excluded from the study. All procedures were carried out in accordance with the Declaration of Helsinki 1975, revised 2013. The study was approved by the institutional review board (5674/2018). Informed consent from the patients was obtained.

\section{Scanning technique [16]}

The patients were imaged in supine position. Dedicated, optimised high-resolution 3D-TOF-MRA protocol with repetition time (TR)/echo time (TE)/flip angle of $19 / 5.7 \mathrm{~ms} / 16^{\circ}$, respectively, with isotropic resolution of $0.6 \times 0.6 \times 0.6 \mathrm{~mm}^{3}$ was used. Scanning parameters included; slice thickness $1.2 \mathrm{~mm}$, $0.6 \mathrm{~mm}$ slice overlap, field of view of $100 \times 100 \mathrm{~mm}$, and matrix $0.6 \times 0.6 \times 0.6 \mathrm{~mm}^{3}$ and TR $-19 \mathrm{~ms}$, $\mathrm{TE}-5.7 \mathrm{~ms}$, and flip angle $-16^{\circ}$. Totally 50 slices covering a volume of $30 \mathrm{~mm}(50 \times 0.6 \mathrm{~mm}$ effective slice thickness) was obtained. The total imaging time was $15 \mathrm{~min}$, of which the 3D-TOF-MRA sequence required $3 \mathrm{~min} 24 \mathrm{~s}$. These axial source images were post-processed by the maximum intensity projection (MIP) algorithm to produce eight projections rotating about the section axis.

\section{Data analysis}

The circle components were divided into two parts; anterior and posterior circles [11]. The anterior circle includes the ICA, the pre-communicating segment of the anterior cerebral arteries (A1) and the AcomA [11]. The posterior circle includes the pre-communicating segment of the posterior cerebral arteries (P1) as well as the PcomAs [11]. The diameters of these components were studied as regards the age and sex groups.

The studied population was subjected to a classification system of COW morphology, based on completeness of the anterior and posterior circle parts according to the potential for collateral flow development (Fig. 1a, b). The anterior circle variant types (a) through (f) are classified as complete types, since their morphology enables collateral flow development through continuity of the anterior channels. Similarly, the posterior circle variant types (a) through (c) are classified as complete types since they possess the potential for collateral flow development through the posterior circle [17].

All component vessels of COW were assessed by measuring the diameter on the original slices and not measuring on 3D reconstructed images to exclude the limitations and pitfalls of post-processing measurements. About the whole COW, the circle was classified as complete, incomplete or partially complete. In complete type all components of the anterior and posterior parts of the circle were visible, continuous and demonstrated diameters of at least $0.8 \mathrm{~mm}$. In incomplete type both the anterior and posterior parts demonstrated a deficient vessel segment (a non-continuous, hypoplastic, or absent segment) [17]. The remaining circles, with a complete either anterior or posterior configuration, were classified as partially complete [18]. 


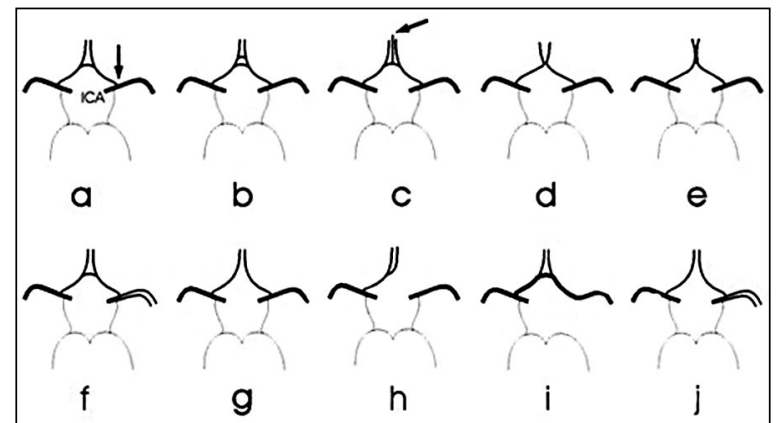

Figure 1. Schematic diagrams of anatomic variations in the anterior part of circle of Willis; a. A single anterior communicating artery (AcomA). The internal carotid artery (ICA) bifurcates into the precommunicating segment of the anterior cerebral artery (ACA) and the middle cerebral artery (MCA); $\boldsymbol{b}$. Two or more AcomAs; c. Medial artery of the corpus callosum arises from the AcomA; d. Fusion of the ACAs occurs over a short distance; e. ACA forms a common trunk and split distally into two postcommunicating segments; $f$. MCA originates from the ICA as two separate trunks; g. Hypoplasia or aplasia of an AcomA; h. One precommunicating segment of an ACA is hypoplastic or absent, the other precommunicating segment gives rise to both post-communicating segments of the ACAs; i. Hypoplasia or absence of ICA on one side with the MCA and ACA supplied from the other side; $j$. Hypoplasia or absence of an AcomA. The MCA arises as two separate trunks [8].

\section{Statistical analysis}

Statistical analysis was performed using the statistical package for the social sciences statistical software (SPSS) version 21.0 (IBM Corporation, Somers, NY, USA). Prevalence of variants of the anterior and posterior parts of the circle was studied. In addition, prevalence of the configuration of the circle and its two parts were also considered. Mean \pm standard deviation (SD) of the diameters of the arteries forming the two parts of the circle was calculated. Finally, comparing the diameter of the arterial circuit regarding gender and age was deliberated. Significance was considered when the $p$-value was $\leq 0.05$.

\section{RESULTS}

Seven anterior circle variations were found. The commonest type was type "a" with a prevalence of $56 \%$, being higher in male $(57.1 \%)$ with equal age groups prevalence. The $2^{\text {nd }}$ common type was type " $g$ " with a prevalence of $24 \%$, being higher in male (66.7\%) with high prevalence (62.5\%) before the age of 40 . The $3^{\text {rd }}$ common type was type " $h$ " $10 \%$, being higher in male (80\%) with $60 \%$ prevalence above the age of 40 . The next coming type was type " $d$ " $4 \%$, being equally occurring in both sexes and totally found above 40 . Types "b, c, e" equally taking place

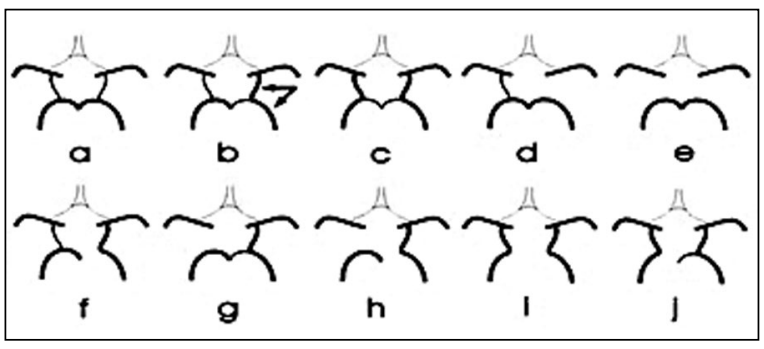

Figure 2. Schematic diagrams of the anatomical variations of the posterior part of circle of Willis; a. Bilateral posterior communicating arteries (PcomAs) are present; b. Posterior cerebral artery (PCA) originates predominantly from the internal carotid artery (ICA). This variant is known as a unilateral foetal type PCA; the PcomA on the other side is patent; c. Bilateral foetal type PCAs with both precommunicating segments of the PCAs patent; d. Unilateral PcomA present; e. Hypoplasia or absence of both PcomAs and isolation of the anterior and posterior parts of the circle at this level; $\mathbf{f}$. Unilateral foetal type PCA and hypoplasia or absence of the precommunicating segment of the PCA; g. Unilateral foetal type PCA and hypoplasia or absence of the contralateral PcomA; h. Unilateral foetal type PCA and hypoplasia or absence of both precommunicating segments of the PCA and the PcomA; i. Bilateral foetal type PCAs with hypoplasia or absence of both precommunicating segments of the PCAs; j. Bilateral foetal type PCAs with hypoplasia or absence of the precommunicating segment of either PCA [8].

$2 \%$ for each one. Finally, types "f, i, j" weren't notable in our study (Fig. 2, Table 1).

Six posterior circle variations were found. The commonest variation was type "a" with a prevalence of $26 \%$, being higher in male $(61.5 \%)$ with nearly equally occurring age. The $2^{\text {nd }}$ common variation was type " $\mathrm{e}$ " with a prevalence of $24 \%$, being higher in male (75\%) and in the elderly studied group (58.3\%). The $3^{\text {rd }}$ common type was type " $h$ " $20 \%$, being higher in male (60\%) with equal age groups prevalence. The next coming type was type " $d$ " $18 \%$ nearly equally occurring in both sexes with high prevalence (72.2\%) above the age of 40 . Types "b, $c$ " take place in $8 \%$ and $4 \%$, respectively. Finally, types " $f, g, i, j$ " weren't notable in our study (Fig. 3, Table 2).

We encountered 28 cases with a complete circle, 38 cases with a partially complete circle and 34 cases with an incomplete circle. The complete anterior circle was encountered in $66 \%$ and the incomplete anterior circle was encountered in 34\%. In addition, the complete posterior circle came across in $38 \%$ and the incomplete posterior circle came across in $62 \%$ (Figs. 2-4, Table 3).

The diameters of the arteries of the anterior and posterior circles were verified in Tables 4 and 5. Finally, the differences between the mean diameter of the 
Table 1. Prevalence of the anterior circle variations

\begin{tabular}{ccccccccc}
\hline \multicolumn{7}{c}{ Anterior circle variations - Count (\%) } & Total \\
\cline { 2 - 6 } & a & b & c & d & e & g & h & \\
\hline Gender: & & & & & & & & \\
Male & $32(57.1 \%)$ & $2(100.0 \%)$ & $2(100.0 \%)$ & $2(50.0 \%)$ & $2(100.0 \%)$ & $16(66.7 \%)$ & $8(80.0 \%)$ & $64(64.0 \%)$ \\
Female & $24(42.9 \%)$ & $0(0.0 \%)$ & $0(0.0 \%)$ & $2(50.0 \%)$ & $0(0.0 \%)$ & $8(33.3 \%)$ & $2(20.0 \%)$ & $36(36.0 \%)$ \\
Age groups: & & & & & & & \\
$\quad<40$ & $27(48.2 \%)$ & $0(0.0 \%)$ & $2(100.0 \%)$ & $0(0.0 \%)$ & $0(0.0 \%)$ & $15(62.5 \%)$ & $4(40.0 \%)$ & $48(48.0 \%)$ \\
$\geq 40$ & $29(51.8 \%)$ & $2(100.0 \%)$ & $0(0.0 \%)$ & $4(100.0 \%)$ & $2(100.0 \%)$ & $9(37.5 \%)$ & $6(60.0 \%)$ & $52(52.0 \%)$ \\
Total & $56(100.0 \%)$ & $2(100.0 \%)$ & $2(100.0 \%)$ & $4(100.0 \%)$ & $2(100.0 \%)$ & $24(100.0 \%)$ & $10(100.0 \%)$ & $100(100.0 \%)$ \\
\hline
\end{tabular}

$\%$ - per cent within anterior circle variations

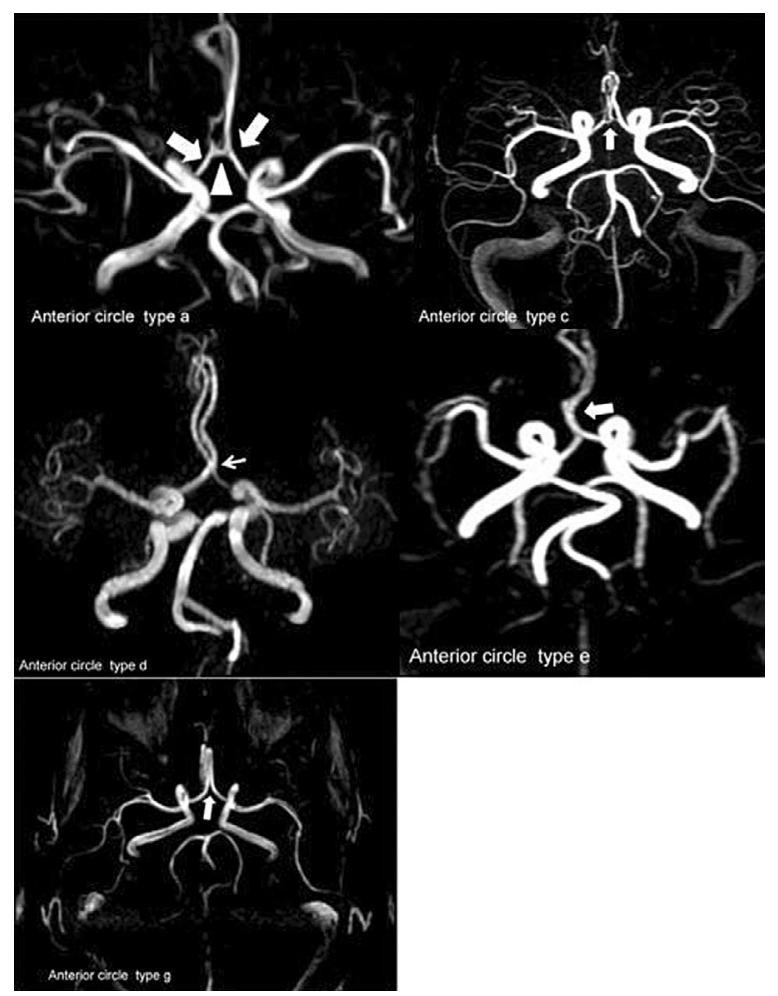

Figure 3. Three-dimensional magnetic resonance angiography of the anterior circle variations; type "a": a single anterior communicating artery (AcomA) (arrowhead) connecting $A 1$ segments of both anterior cerebral arteries (ACAs) (arrows); type "c": absent AcomA (arrow); type "d": a median artery of corpus callosum arising from the AcomA (arrow); type "e": ACAs fusing to form a common trunk (arrow); type "g": fusion of the ACAs for a short segment (arrow).

arteries of the anterior and posterior circles regarding age and sex were also accomplished (Tables 4, 5).

\section{DISCUSSION}

Vascular variation has been studied using several methods including autopsy, computed tomography angiography and MRA [24]. Except for PcomA, MRA

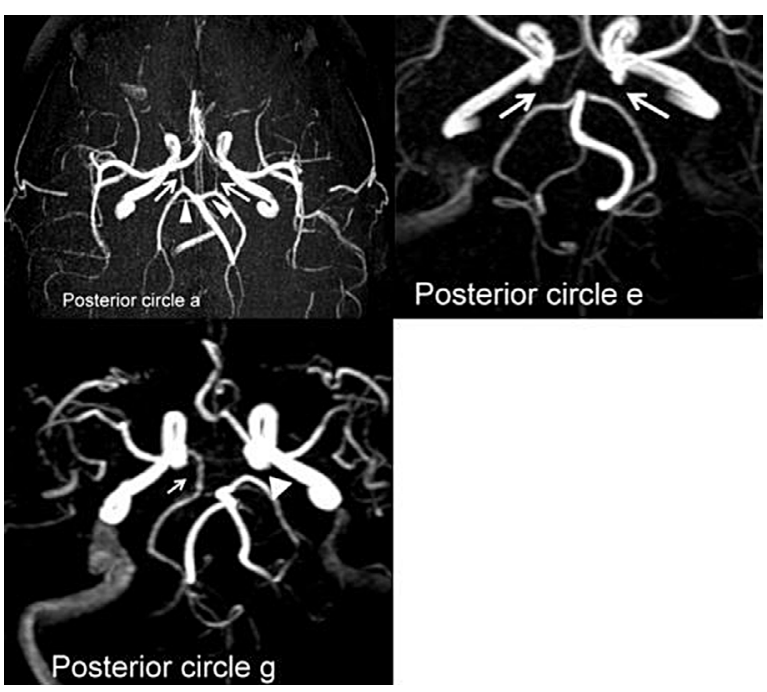

Figure 4. Three-dimensional magnetic resonance angiography of the posterior circle variations. type "a": bilateral posterior communicating arteries (PcomAs) (arrows) joining the P1 segments of the posterior cerebral artery (PCA) (arrowheads); type "e": bilateral absent PcomAs (arrows); type "g": right foetal type PCA (arrow) arising from the internal carotid artery with absent left posterior communicating artery (arrowhead).

was found to be the most sensitive method in the evaluation of COW arteries [24].

The present work proved the previous studies of the difference between the anterior and the posterior circles, in respect to the type of anomaly [2].

The anterior circle variations are of great clinical importance as cerebral infarct due to occlusion of ACA is common [24]. We detected seven anterior circle variations out of the ten reported types. The commonest anterior circle variation was type "a" (classic type) with a prevalence of $56 \%$ in our study compared to $47.2 \%$ in Polish population and $76 \%$ in Chinese population $[15,17]$.

The $2^{\text {nd }}$ common anterior circle variation and the commonest anomaly was type " $g$ " (hypoplasia or 
Table 2. Prevalence of the posterior circle variations

\begin{tabular}{|c|c|c|c|c|c|c|c|}
\hline & \multicolumn{7}{|c|}{ Posterior circle variations — Count (\%) } \\
\hline & a & b & c & d & e & $\mathbf{h}$ & Total \\
\hline \multicolumn{8}{|l|}{ Gender: } \\
\hline Male & $16(61.5 \%)$ & $6(75.0 \%)$ & $2(50.0 \%)$ & $10(55.6 \%)$ & $18(75.0 \%)$ & $12(60.0 \%)$ & $64(64.0 \%)$ \\
\hline Female & $10(38.5 \%)$ & $2(25.0 \%)$ & $2(50.0 \%)$ & $8(44.4 \%)$ & $6(25.0 \%)$ & $8(40.0 \%)$ & $36(36.0 \%)$ \\
\hline \multicolumn{8}{|l|}{ Age groups: } \\
\hline$<40$ & $14(53.8 \%)$ & $6(75.0 \%)$ & $3(75.0 \%)$ & $5(27.8 \%)$ & $10(41.7 \%)$ & $10(50.0 \%)$ & $48(48.0 \%)$ \\
\hline$\geq 40$ & $12(46.2 \%)$ & $2(25.0 \%)$ & $1(25.0 \%)$ & $13(72.2 \%)$ & $14(58.3 \%)$ & $10(50.0 \%)$ & $52(52.0 \%)$ \\
\hline Total & $26(100.0 \%)$ & $8(100.0 \%)$ & $4(100.0 \%)$ & $18(100.0 \%)$ & $24(100.0 \%)$ & $20(100.0 \%)$ & $100(100.0 \%)$ \\
\hline
\end{tabular}

$\%$ - per cent within posterior circle variations

Table 3. Prevalence of the configuration of the circle of Willis according to sex

\begin{tabular}{|c|c|c|c|c|c|c|c|c|c|c|}
\hline & \multicolumn{4}{|c|}{ Configuration of the circle } & \multicolumn{3}{|c|}{ Configuration of the anterior circle } & \multicolumn{3}{|c|}{ Configuration of the posterior circle } \\
\hline & $\begin{array}{l}\text { Entirely } \\
\text { complete }\end{array}$ & $\begin{array}{l}\text { Partially } \\
\text { complete }\end{array}$ & Incomplete & Total & Complete & Incomplete & Total & Complete & Incomplete & Total \\
\hline $\begin{array}{l}\text { Male } \\
\text { (\% within gender) }\end{array}$ & $\begin{array}{c}16 \\
25.0 \%\end{array}$ & $\begin{array}{c}24 \\
37.5 \%\end{array}$ & $\begin{array}{c}24 \\
37.5 \%\end{array}$ & $\begin{array}{c}64 \\
100.0 \%\end{array}$ & $\begin{array}{c}40 \\
62.5 \%\end{array}$ & $\begin{array}{c}24 \\
37.5 \%\end{array}$ & $\begin{array}{c}64 \\
100 \%\end{array}$ & $\begin{array}{c}24 \\
37.5 \%\end{array}$ & $\begin{array}{c}40 \\
62.5 \%\end{array}$ & $\begin{array}{c}64 \\
100.0 \%\end{array}$ \\
\hline $\begin{array}{l}\text { Female } \\
\text { (\% within gender) }\end{array}$ & $\begin{array}{c}12 \\
33.3 \%\end{array}$ & $\begin{array}{c}14 \\
38.9 \%\end{array}$ & $\begin{array}{c}10 \\
27.8 \%\end{array}$ & $\begin{array}{c}36 \\
100.0 \%\end{array}$ & $\begin{array}{c}26 \\
72.2 \%\end{array}$ & $\begin{array}{c}10 \\
27.8 \%\end{array}$ & $\begin{array}{c}36 \\
100 \%\end{array}$ & $\begin{array}{c}14 \\
38.9 \%\end{array}$ & $\begin{array}{c}22 \\
61.1 \%\end{array}$ & $\begin{array}{c}36 \\
100.0 \%\end{array}$ \\
\hline $\begin{array}{l}\text { Total } \\
\text { (\% of total) }\end{array}$ & $\begin{array}{c}28 \\
28.0 \%\end{array}$ & $\begin{array}{c}38 \\
38.0 \%\end{array}$ & $\begin{array}{c}34 \\
34.0 \%\end{array}$ & $\begin{array}{c}100 \\
100.0 \%\end{array}$ & $\begin{array}{c}66 \\
66 \%\end{array}$ & $\begin{array}{c}34 \\
34 \%\end{array}$ & $\begin{array}{c}100 \\
100 \%\end{array}$ & $\begin{array}{c}38 \\
38.0 \%\end{array}$ & $\begin{array}{c}62 \\
62.0 \%\end{array}$ & $\begin{array}{c}100 \\
100.0 \%\end{array}$ \\
\hline
\end{tabular}

Table 4. The mean diameters of the arteries of the anterior circle

\begin{tabular}{|c|c|c|c|c|c|c|c|c|c|c|c|c|}
\hline & & & $\begin{array}{c}\text { Right A1 } \\
{[\mathrm{mm}]}\end{array}$ & $\mathbf{P}$ & $\begin{array}{c}\text { Left A1 } \\
\text { [mm] }\end{array}$ & $\mathbf{P}$ & $\begin{array}{c}\text { AcomA } \\
{[\mathrm{mm}]}\end{array}$ & $\mathbf{P}$ & $\begin{array}{c}\text { Right ICA } \\
{[\mathrm{mm}]}\end{array}$ & $\mathbf{P}$ & $\begin{array}{c}\text { Left ICA } \\
{[\mathrm{mm}]}\end{array}$ & $\mathbf{P}$ \\
\hline \multirow[t]{6}{*}{ Sex } & Male & $\mathrm{N}$ & 58 & $0.002^{*}$ & 63 & $0.05^{*}$ & 38 & $0.04^{*}$ & 64 & $0.000^{*}$ & 64 & 0.07 \\
\hline & & Mean $\pm S D$ & $2.4 \pm 0.5$ & & $2.3 \pm 0.6$ & & $1.5 \pm 0.4$ & & $5.0 \pm 0.8$ & & $4.7 \pm 1.0$ & \\
\hline & & Min/Max & $1.5 / 3.4$ & & $1.3 / 3.5$ & & $1.0 / 2.5$ & & $3.7 / 7.0$ & & $3.0 / 7.0$ & \\
\hline & Female & $\mathrm{N}$ & 34 & & 35 & & 24 & & 36 & & 36 & \\
\hline & & Mean \pm SD & $2.0 \pm 0.5$ & & $2.1 \pm 0.4$ & & $1.3 \pm 0.3$ & & $4.4 \pm 0.7$ & & $4.4 \pm 0.9$ & \\
\hline & & Min/Max & $1.3 / 3.4$ & & $1.3 / 3.0$ & & $1.0 / 2.0$ & & $3.3 / 6.0$ & & $3.0 / 6.5$ & \\
\hline \multirow{6}{*}{$\begin{array}{l}\text { Age } \\
\text { group }\end{array}$} & $<40$ & $\mathrm{~N}$ & 44 & $0.000^{*}$ & 47 & 0.847 & 27 & 0.979 & 48 & 0.07 & 48 & 0.167 \\
\hline & & Mean \pm SD & $2.4 \pm 0.6$ & & $2.2 \pm 0.5$ & & $1.4 \pm 0.4$ & & $4.9 \pm 0.9$ & & $4.7 \pm 1.1$ & \\
\hline & & Min/Max & $1.5 / 3.4$ & & $1.3 / 3.5$ & & $1.0 / 2.5$ & & $3.6 / 7.0$ & & $3.0 / 7.0$ & \\
\hline & $\geq 40$ & $\mathrm{~N}$ & 48 & & 51 & & 35 & & 52 & & 52 & \\
\hline & & Mean \pm SD & $2.0 \pm 0.4$ & & $2.3 \pm 0.5$ & & $1.4 \pm 0.4$ & & $4.6 \pm 0.7$ & & $4.5 \pm 0.9$ & \\
\hline & & Min/Max & $1.3 / 3.0$ & & $1.3 / 3.5$ & & $1.0 / 2.5$ & & $3.3 / 6.7$ & & $3.0 / 7.0$ & \\
\hline \multirow[t]{3}{*}{ Total } & & $\mathrm{N}$ & 92 & & 98 & & 62 & & 100 & & 100 & \\
\hline & & Mean \pm SD & $2.2 \pm 0.5$ & & $2.3 \pm 0.5$ & & $1.4 \pm 0.4$ & & $4.8 \pm 0.8$ & & $4.6 \pm 1.0$ & \\
\hline & & Min/Max & $1.3 / 3.4$ & & $1.3 / 3.5$ & & $1.0 / 2.5$ & & $3.3 / 7.0$ & & $3.0 / 7.0$ & \\
\hline
\end{tabular}

${ }^{*}$ Statistical significance; Acom — anterior communicating artery; ICA — internal carotid artery; SD — standard deviation; Min — minimum; Max — maximum

aplasia of the AcomA) which existed in $24 \%$ of the cases. Many authors reported hypoplastic vessels as the most common anomaly observed in COW [1].
The anterior circle type " $\mathrm{b}$ " (two or more AcomA; fenestrated AcomA) existed in $2 \%$ of our studied cases. Type " $b$ " variation mostly developed from the 
Table 5. The mean diameters of the arteries of the posterior circle

\begin{tabular}{|c|c|c|c|c|c|c|c|c|c|c|}
\hline & & & $\begin{array}{c}\text { Right P1 } \\
\text { [mm] }\end{array}$ & $\mathbf{P}$ & $\begin{array}{c}\text { Left P1 } \\
{[\mathrm{mm}]}\end{array}$ & $\mathbf{P}$ & $\begin{array}{l}\text { Right PcomA } \\
{[\mathrm{mm}]}\end{array}$ & $\mathbf{P}$ & $\begin{array}{l}\text { Left PcomA } \\
{[\mathrm{mm}]}\end{array}$ & $\mathbf{P}$ \\
\hline \multirow[t]{6}{*}{ Sex } & Male & $\mathrm{N}$ & 64 & 0.173 & 64 & 0.543 & 36 & 0.306 & 34 & $0.004^{*}$ \\
\hline & & Mean \pm SD & $2.1 \pm 0.5$ & & $2.0 \pm 0.4$ & & $1.5 \pm 0.5$ & & $1.8 \pm 0.6$ & \\
\hline & & Min/Max & $1.2 / 3.0$ & & $1.0 / 3.0$ & & $0.7 / 3.0$ & & $1.0 / 3.0$ & \\
\hline & Female & $\mathrm{N}$ & 36 & & 36 & & 20 & & 24 & \\
\hline & & Mean \pm SD & $1.9 \pm 0.5$ & & $2.0 \pm 0.5$ & & $1.7 \pm 0.5$ & & $1.4 \pm 0.5$ & \\
\hline & & Min/Max & $0.8 / 3.3$ & & $1.0 / 2.5$ & & $1.3 / 2.7$ & & $0.8 / 2.5$ & \\
\hline \multirow[t]{6}{*}{ Age group } & $<40$ & $\mathrm{~N}$ & 48.0 & 0.117 & 48.0 & 0.497 & 32.0 & $0.009^{*}$ & 29.0 & 0.335 \\
\hline & & Mean \pm SD & $1.9 \pm 0.6$ & & $2.0 \pm 0.4$ & & $1.7 \pm 0.5$ & & $1.6 \pm 0.5$ & \\
\hline & & Min/Max & $0.8 / 3.3$ & & $1.0 / 3.0$ & & $1.0 / 3.0$ & & $0.8 / 2.5$ & \\
\hline & $\geq 40$ & $\mathrm{~N}$ & 52 & & 52 & & 24 & & 29 & \\
\hline & & Mean \pm SD & $2.1 \pm 0.4$ & & $2.0 \pm 0.4$ & & $1.4 \pm 0.4$ & & $1.7 \pm 0.7$ & \\
\hline & & Min/Max & $1.3 / 3.0$ & & $1.0 / 2.6$ & & $0.7 / 2.1$ & & $1.0 / 3.0$ & \\
\hline \multirow[t]{3}{*}{ Total } & & $\mathrm{N}$ & 100 & & 100 & & 56 & & 58 & \\
\hline & & Mean \pm SD & $2.0 \pm 0.5$ & & $2.0 \pm 0.4$ & & $1.6 \pm 0.5$ & & $1.7 \pm 0.6$ & \\
\hline & & Min/Max & $0.8 / 3.3$ & & $1.0 / 3.0$ & & $0.7 / 3.0$ & & $0.8 / 3.0$ & \\
\hline
\end{tabular}

*Statistical significance; PComA — posterior communicating artery; SD — standard deviation; Min — minimum; Max — maximum

incomplete fusion of the plexiform structure connecting both ACA during the embryonic life [20]. Such anomaly is important in planning of interventional measures [9]. Both types " $g, b$ " was found to be higher among patients with cerebral occlusive disease and aneurysm compared to normal patients [13]. In addition, fenestration can pose unexpected difficulties in surgical treatment because of the accompanying aneurysms [9].

Regarding the posterior circle variations, 6 variations were encountered in our study out of the 10 variations reported in other studies [8]. Posterior circle variations may be the result of rapid growth of the occipital lobe in the foetal period [26].

Posterior circles types " $d-h$ " are characterised by hypoplasia/absent PcomA. In our study; the only observed of these types are types "d, e, h" (18\%, $24 \%, 20 \%$ ) which constitute about $62 \%$ of the all studied cases. The first type was equally occurring in both sexes, while the last two types were higher in male. The PcomA hypoplasia is a contributor to risk of ischaemic stroke, even in the absence of ICA occlusion [4].

In our study, the prevalence of the entire complete type (the classic or textbook type) was encountered only $28 \%$ (with higher prevalence in male; 16/28), coming after the partially incomplete and incomplete types (38\%, 35\%, respectively). Similar entire complete type prevalence was encountered in Chi- nese study (27\%) [17]. The prevalence of complete circle was low in Sri Lankans (14.2\%) [6], moderate in Indian population (45.2\% and 53.2\%) [12, 22] and extremely high in the Japanese population (89.7\%) [25]. Surprisingly, a wide range of complete circle was observed in the western population studies; from 28\% (an MRA study) to $52.3 \%$ (an autopsy study) $[1,16]$. The wide range in the prevalence of the typical formation among numerous races may be related to environmental, genetic, regional, and haemodynamic factors or the combination of these factors.

The prevalence of complete anterior circle in our study was $66 \%$. In earlier studies, the prevalence of complete anterior circle varied from $74 \%$ to $90 \%$ in different ethnic groups $[7,16]$. The prevalence of complete posterior circle in our study was $38 \%$. Higher prevalence was reported in earlier studies; $48 \%$ in Ross's study [23] and 52\% in Krabbe-Hartkamp's study [16].

The prevalence of partially complete circle and incomplete circle in the present work encountered in $38 \%$ and $34 \%$, respectively (total prevalence was $72 \%$ ). The reported incidence of absent vessels in COW leading to incomplete circle ranges from $0.6 \%$ [2] to $17 \%$ [19]. We found the incomplete anterior circle in $34 \%$ (10\% isolated incomplete anterior circle and $24 \%$ combined incomplete anterior and posterior circles) and the incomplete posterior circle came across in $62 \%$ (38\% isolated incomplete posterior 
circle and $24 \%$ combined incomplete anterior and posterior circles). According to these findings, most of the circle variations were found to be the posterior circle, which is consistent with the literature on the Turkish population [13]. A direct relation between incompleteness of the posterior circle type and development of migraine was reported [3].

We studied the variations of COW in two different age groups as haemodynamic changes are not limited to the embryonic period and can disturb the formation of the circle in the first decade of life [11].

\section{CONCLUSIONS}

In conclusion, the prevalence of complete COW (classic or textbook type) was encountered only $28 \%$ of the studied cases. Variations of COW were found to be more common in the posterior circulation (62\%). The incomplete anterior circle was found in 34\% and it is mostly caused by hypoplasia or aplasia of the AcomA which was found to be more common compared to the literature.

\section{REFERENCES}

1. Alpers BJ, Berry RG. Circle of Willis in cerebral vascular disorders. The anatomical structure. Arch Neurol. 1963; 8: 398-402, doi: 10.1001/archneur.1963.00460040068006, indexed in Pubmed: 14012272.

2. Alpers BJ, Berry RG. Anatomical studies of the circle of Willis in normal brain. AMA Arch Neurol Psychiatry. 1959; 81(4): 409-418.

3. Bugnicourt JM, Garcia PY, Peltier J, et al. Incomplete posterior circle of willis: a risk factor for migraine? Headache. 2009; 49(6): 879-886, indexed in Pubmed: 19562826.

4. Chuang YM, Liu CY, Pan PJ. Posterior communicating artery hypoplasia as a risk factor for acute ischemic stroke in the absence of carotid artery occlusion. J Clin Neurosci. 2008; 15(12): 1376-1381.

5. Cui Y, Xu T, Chen J, et al. Anatomic variations in the anterior circulation of the circle of Willis in cadaveric human brains. Int J Clin Exp Med. 2015; 8(9): 15005-15010.

6. De Silva KR, Silva R, Gunasekera WS, et al. Prevalence of typical circle of Willis and the variation in the anterior communicating artery: A study of a Sri Lankan population. Ann Indian Acad Neurol. 2009; 12(3): 157-161.

7. Eftekhar B, Dadmehr M, Ansari S, et al. Are the distributions of variations of circle of Willis different in different populations? - Results of an anatomical study and review of literature. BMC Neurol. 2006; 6: 22, doi: 10.1186/14712377-6-22, indexed in Pubmed: 16796761.

8. El-Barhoun EN, Gledhill SR, Pitman AG, et al. Circle of Willis artery diameters on MR angiography: an Australian reference database. J Med Imaging Radiat Oncol. 2009; 53(3): 248-260.

9. Goddard AJ, Annesley-Williams D, Guthrie J, et al. Duplication of the vertebral artery: report of two cases and review of the literature. Neuroradiology. 2001; 43(6): 477-480.
10. Iqbal S. A comprehensive study of the anatomical variations of the circle of willis in adult human brains. J Clin Diagn Res. 2013; 7(11): 2423-2427.

11. Jalali Kondori, B, Azemati F, Dadseresht S. Magnetic Resonance Angiographic Study of Anatomic Variations of the Circle of Willis in a Population in Tehran. Arch Iran Med. 2017; 20(4): 235-239.

12. Kapoor K, Singh B, Dewan LI. Variations in the configuration of the circle of Willis. Anat Sci Int. 2008; 83(2): 96-106, doi: 10.1111/j.1447-073X.2007.00216.x, indexed in Pubmed: 18507619.

13. Karatas A, Yilmaz H, Coban G, et al. The Anatomy of Circulus Arteriosus Cerebri (Circle of Willis): A Study in Turkish Population. Turk Neurosurg. 2016; 26(1): 54-61.

14. Kato T, Indo T, Yoshida E, et al. Contrast-enhanced 2D cine phase MR angiography for measurement of basilar artery blood flow in posterior circulation ischemia. AJNR Am J Neuroradiol. 2002; 23(8): 1346-1351.

15. Klimek-Piotrowska W, Kopeć M, Kochana M, et al. Configurations of the circle of Willis: a computed tomography angiography based study on a Polish population. Folia Morphol. 2013; 72(4): 293-299.

16. Krabbe-Hartkamp MJ, van der Grond MJ, de Leeuw FE, et al. Circle of Willis: morphologic variation on three-dimensional time-of-flight MR angiograms. Radiology. 1998; 2017(1): 103-111.

17. Li Q, Li J, Lv F, et al. A multidetector CT angiography study of variations in the circle of Willis in a Chinese population. J Clin Neurosci. 2011; 18(3): 379-383.

18. Naveen SR, Bhat V, Karthik GA. Magnetic resonance angiographic evaluation of circle of Willis: A morphologic study in a tertiary hospital set up. Ann Indian Acad Neurol. 2015; 18(4): 391-397.

19. Ozaki $\mathrm{T}$, Handa $\mathrm{H}$, Tomimoto $\mathrm{K}$, et al. Anatomical variations of the arterial system of the base of the brain. Nihon Geka Hokan. 1977; 46(1): 3-17.

20. Puchades-Orts A, Nombela-Gomez M, Ortuño-Pacheco G. Variation in form of circle of Willis: some anatomical and embryological considerations. Anat Rec. 1976; 185(1): 119-123.

21. Qiu C, Zhang Y, Jiang S, et al. MRA study on variation of the circle of willis in healthy Chinese male adults. Biomed Res Int. 2015: 976340.

22. Reddy DR, Prabhakar V, Rao BD. Anatomical study of circle of Willis. Neurol India. 1972; 20(1): 8-12, indexed in Pubmed: 4641044.

23. Ross MR, Pelc NJ, Enzmann DR. Qualitative phase contrast MRA in the normal and abnormal circle of Willis. AJNR Am J Neuroradiol. 1993; 14(1): 19-25.

24. Shatri J, Cerkezi S, Ademi V, et al. Anatomical variations and dimensions of arteries in the anterior part of the circle of Willis. Folia Morphol. 2019; 78(2): 259-266.

25. Tanaka H, Fujita N, Enoki T, et al. Relationship between variations in the circle of Willis and flow rates in internal carotid and basilar arteries determined by means of magnetic resonance imaging with semiautomated lumen segmentation: reference data from 125 healthy volunteers. AJNR Am J Neuroradiol. 2006; 27(8): 1770-1775 .

26. Van Overbeeke JJ, Hillen B, Tulleken CA. A comparative study of the circle of Willis in fetal and adult life. The configuration of the posterior bifurcation of the posterior communicating artery. J Anat. 1991; 176: 45-54, indexed in Pubmed: 1917674. 